\title{
The Therapeutic Effects of Completing Autobiographical Memory Questionnaires for Positive and Negative Events: An Experimental Approach
}

\author{
Adriel Boals · Lisa M. Hathaway - David C. Rubin
}

Published online: 6 November 2011

(C) Springer Science+Business Media, LLC 2011

\begin{abstract}
Rubin et al. (Cognit Ther Res 34:35-48, 2010) demonstrated that completing autobiographical memory questionnaires about a very negative event leads to decreases in levels of distress related to that event. However, a limitation of their methodology was that perhaps completing the memory questionnaire about any autobiographical memory could produce the reported effects. In the current study, 238 participants nominated a very negative and a very positive event from their lives. Participants were then randomly assigned to complete autobiographical memory questionnaires about either their nominated negative or nominated positive event. The results generally replicated the pattern reported in Rubin et al. In comparison to participants who completed questionnaires about a positive event, participants who completed the memory questionnaires about their nominated negative event evidenced decreases in emotional reactions and distress levels. Implications for completing autobiographical memory questionnaires about negative events as a possible therapeutic tool are discussed.
\end{abstract}

Keywords Stress - Coping - Autobiographical memory · Exposure therapy $\cdot$ PTSD

\footnotetext{
A. Boals $(\bowtie) \cdot$ L. M. Hathaway

Department of Psychology, University of North Texas,

Box 311280, Denton, TX 76203, USA

e-mail: adriel@unt.edu

D. C. Rubin

Department of Psychology and Neuroscience, Duke University, Durham, NC, USA

D. C. Rubin

Center on Autobiographical Memory Research,

Aarhus University, Aarhus, Denmark
}

Most people will experience at least one traumatic event during their lifetime (Kessler et al. 1995), which can result in a myriad of negative consequences, including depression and anxiety disorders (Breslau et al. 1991), low life satisfaction (Keim et al. 2003), poor physical health (Buckley et al. 2004), poor sleep quality (Krakow et al. 2001), cognitive impairments (Koso and Hansen 2006), poor anger management (Frueh et al. 1997), substance abuse (Kilpatrick et al. 2003), and family and marital problems (Jordan et al. 1992). Recent studies have revealed that stressful events that fall short of meeting the Diagnostic and Statistical Manual of Mental Disorders, fourth editiontext revision (DSM-IV-TR, American Psychiatric Association [APA] 2000) criteria for a traumatic event, such as relationship breakups, death of a loved one, and parents divorcing, can result in mental health symptoms comparable to those caused by traumatic events (Boals and Schuettler 2009; Gold et al. 2005; Long et al. 2008; Van Hooff et al. 2009). Thus the experiencing of stressful major life events has the ability to cause mental health problems and impairments in everyday functioning.

Fortunately, there are a number of known interventions that are effective at reducing the negative impact of these events. In extreme cases in which the individual develops a clinical case of posttraumatic stress disorder (PTSD), exposure therapy has been shown to effectively treat this condition and lead to drastic reductions in symptoms (Institute of Medicine 2008). The mechanism behind the efficacy of exposure therapy appears to be extinction. The repeated vivid reliving of the trauma in a safe environment eventually leads to extinction of the stress response. Reliving the event in a safe environment is believed to give the client a sense of competence, mastery, and safety and the client no longer needs to avoid the traumatic memory (Nemeroff et al. 2006). In the case of stressful, but 
non-traumatic events, a reduction in symptoms can be achieved through interventions that do not require the presence of a mental health professional. For example, participants who are asked to write about their 'deepest thoughts and feelings' in regards to a stressful event (known as the expressive writing or emotional disclosure intervention) experience both mental health and physical health benefits (Frattaroli 2006). Although the mechanisms behind the efficacy of this intervention are probably numerous (Sloan and Marx 2004), extinction is likely one of the primary mechanisms (Frattaroli 2006). Thus the reliving of a stressful or traumatic event in a safe environment appears to be a basis of effective coping.

Consistent with this line of reasoning, Rubin et al. (2010) examined whether completing questionnaires about a stressful event would lead to reductions in distress levels associated with that event. The questionnaires they used were the Autobiographical Memory Questionnaire (AMQ) and the Impact of Events Scale (IES). The AMQ was designed to assess phenomenological features of any autobiographical memory. The questionnaire consists of 28 items including emotional intensity, sensory features, vividness, field/observer perspective, remember/know judgments, and confidence in accuracy. The set of questions has been used extensively in earlier studies of autobiographical memory and so we know a great deal about how the ratings normally function and relate to each other (Rubin et al. 2003a, 2008, 2011). Completing the AMQ requires the respondent to reinstate the memory and consider sensory, narrative, and emotional properties of the memory. Thus completing the AMQ activates comprehensive reliving of the memory. The IES asks the respondents to rate the frequency of intrusive and avoidant thoughts related to the stressful event.

We would not expect that interventions that effectively reduce the levels of distress associated with an event would lead to decreases in all AMQ items. Rather, we would expect effective interventions to produce decreases only in the aspects of autobiographical memory that differ between stressful and non-stressful memories. A series of studies have demonstrated that stressful memories are more emotional, have higher levels of involuntary recall, and are more central to the life story. All other properties of autobiographical memories as measured by the AMQ evidence no differences between stressful and non-stressful memories. This pattern of results has been found in both clinical (Rubin et al. 2011) and non-clinical (Rubin et al. 2008) samples. A total of 250 participants from three related studies nominated a very negative event from their lives and then completed the AMQ and IES in reference to this event. The result was significant decreases in the AMQ items related to emotion and involuntary recall, the same items that differentiate stressful from non- stressful memories. There were also significant decreases in IES scores. In a follow-up experiment, 208 participants nominated a negative event, and then were randomly assigned to either complete the AMQ and IES in reference to this event, or to simply nominate other events from their lives. The results of this experiment replicated those of the first three studies. That is, there were significant decreases in items related to emotions and involuntary recall.

The purpose of the current study was to replicate the findings from Rubin et al. (2010, Experiment 4) that completing the AMQ and IES in reference to a negative event produces decreases in emotional reactions and involuntary recall related to the negative event. In the Rubin et al. experiment, participants in the control group nominated a negative event at Time 1 and then nominated other events from their lives. In contrast, participants in the experimental condition completed the AMQ and IES in reference to their negative event in lieu of nominating other life events. One limitation of this design is that perhaps completing the AMQ for any event would lead to the observed decreases in emotions and distress.

In the current study, all participants nominated a very negative and a very positive event from their lives. The participants were randomly assigned to complete the AMQ in reference to either their nominated negative event or their nominated positive event. If the results replicate, then we can conclude that any observed effects are due specifically to completing the AMQ and IES in reference to the negative event, and rule out the possibility that the effects might be caused by completing these questionnaires in reference to any event. Indeed, if extinction is the mechanism behind the therapeutic effects of completing memory questionnaires, then an effect should only be observed when memory questionnaires are completed in reference to the negative event. Completing the same memory questionnaires about an unrelated event should have no effect on the negative event. The hypothesis is that participants assigned to complete the AMQ and IES in reference to a nominated very negative event will evidence the same pattern of results reported in Rubin et al. In Rubin et al. (Experiment 4), the strongest and most consistent effects of completing the memory questionnaires were found for AMQ items related to emotional intensity and visceral emotional reactions (see Table 1 for a list of AMQ items). Thus we expect to find similar decreases in the current study. Rubin et al. also reported significant decreases in the IES and AMQ items related to availability, reliving, see, and story that we might expect to replicate in the current study. We expect no changes in measures of recollection and belief (except reliving), sensory features, and language, narrative, and specificity. In addition, since Rubin et al. found a weak effect of time-since-event, we included an item about how long ago their nominated negative event occurred so that this variable could be covaried. 
Table 1 Changes in negative event condition from Time 1 to Time 2 and differences between conditions at Time 2

\begin{tabular}{|c|c|c|c|c|c|}
\hline \multirow[t]{2}{*}{ Ratings of a negative memory } & \multicolumn{3}{|c|}{ Mean (SD) of negative memory } & \multicolumn{2}{|l|}{$F$ values $\left(\eta^{2}\right)$} \\
\hline & $\begin{array}{l}\text { A } \\
\text { Neg@ T1 }\end{array}$ & $\begin{array}{l}\text { B } \\
\text { Neg@ T1 } \\
\text { Neg@ T2 }\end{array}$ & $\begin{array}{l}\mathrm{C} \\
\text { Pos @ T1 } \\
\text { Neg @ T2 }\end{array}$ & $\begin{array}{l}\text { Within } \\
\text { B-A }\end{array}$ & $\begin{array}{l}\text { Between } \\
\text { B-C }\end{array}$ \\
\hline \multicolumn{6}{|l|}{ Recollection and belief } \\
\hline I am reliving the original event. & $3.19(1.76)$ & $2.89(1.72)$ & $3.41(1.87)$ & $0.49(0.01)$ & $3.89(0.02)^{*}$ \\
\hline I travel back to the time when it happened. & $3.90(1.82)$ & $3.43(1.67)$ & $4.07(1.81)$ & $2.43(0.03)$ & $6.74(0.03)^{*}$ \\
\hline I remember it rather than just knowing it happened. & $5.44(1.60)$ & $5.46(1.46)$ & $5.45(1.44)$ & $0.69(0.01)$ & $0.01(0.01)$ \\
\hline I believe the event in my memory really occurred. & $5.77(1.54)$ & $6.09(1.17)$ & $6.08(1.18)$ & $1.08(0.01)$ & $0.01(0.01)$ \\
\hline I could be persuaded that my memory was wrong. & $2.31(1.26)$ & $2.35(1.29)$ & $2.44(1.26)$ & $5.60(0.05)^{*}$ & $0.32(0.01)$ \\
\hline \multicolumn{6}{|l|}{ Sensory } \\
\hline I can see it in my mind. & $4.72(1.52)$ & $4.57(1.39)$ & $4.80(1.40)$ & $0.28(0.01)$ & $1.54(0.01)$ \\
\hline I see it out of my own eyes. (field/observer) & $4.84(2.00)$ & 4.69 (1.97) & $5.00(1.79)$ & $1.08(0.01)$ & $1.53(0.01)$ \\
\hline I can recall the setting where it occurred. & $5.78(1.50)$ & $5.56(1.68)$ & $5.67(1.38)$ & $3.17(0.03)^{\dagger}$ & $0.32(0.01)$ \\
\hline I can hear it in my mind. & $4.08(1.80)$ & $3.76(1.68)$ & $4.09(1.64)$ & $0.22(0.01)$ & $2.48(0.01)$ \\
\hline \multicolumn{6}{|l|}{ Emotions } \\
\hline I feel the same emotions I felt then. & $3.73(1.76)$ & $3.49(1.65)$ & $3.72(1.71)$ & $0.68(0.01)$ & $0.88(0.01)$ \\
\hline I feel the emotions as strongly as I did then. & $3.34(1.71)$ & $3.05(1.58)$ & $3.41(1.70)$ & $6.73(0.07)^{*}$ & $2.15(0.01)$ \\
\hline The emotions are extremely positive. & $1.95(1.24)$ & $2.02(1.25)$ & $2.17(1.44)$ & $0.91(0.01)$ & $0.56(0.01)$ \\
\hline The emotions are extremely negative. & $5.26(1.70)$ & $5.00(1.70)$ & $5.16(1.62)$ & $8.67(0.09)^{*}$ & $0.51(0.01)$ \\
\hline The emotions are extremely intense. & $4.09(1.69)$ & $3.41(1.60)$ & $4.00(1.72)$ & $22.13(0.19)^{* * *}$ & $5.98(0.03)^{*}$ \\
\hline I feel my heart pound or race. & $2.95(1.79)$ & $2.36(1.42)$ & $3.10(1.80)$ & $12.82(0.12)^{* * *}$ & $10.50(0.05)^{* *}$ \\
\hline I feel tense all over. & $0.97(1.82)$ & $2.48(1.40)$ & $3.00(1.82)$ & $8.27(0.08)^{* *}$ & $5.39(0.03)^{*}$ \\
\hline I feel sweaty or clammy. & $2.15(1.58)$ & $1.80(1.11)$ & $2.32(1.49)$ & $2.09(0.02)$ & $7.62(0.04)^{* *}$ \\
\hline I feel knots, cramps, or butterflies in my stomach. & $2.58(1.81)$ & $2.11(1.39)$ & $2.74(1.83)$ & $3.45(0.04)^{\dagger}$ & $7.79(0.04)^{* *}$ \\
\hline \multicolumn{6}{|l|}{ Availability } \\
\hline This memory has come to me out of the blue. & $3.35(1.79)$ & $3.09(1.37)$ & $3.50(1.62)$ & $1.25(0.01)$ & $4.21(0.02)^{*}$ \\
\hline I have thought about this event. & $4.65(1.65)$ & $4.44(1.55)$ & $4.47(1.55)$ & $4.19(0.04)^{*}$ & $0.08(0.01)$ \\
\hline I have talked about this event. & $3.87(1.67)$ & $3.60(1.59)$ & $3.93(1.66)$ & $5.40(0.06)^{*}$ & $2.56(0.01)$ \\
\hline \multicolumn{6}{|l|}{ Language, narrative, and specificity } \\
\hline It comes to me in words. & $3.25(1.64)$ & $2.96(1.61)$ & $3.19(1.56)$ & $0.17(0.01)$ & $0.93(0.01)$ \\
\hline It comes to me as a coherent story. & $4.30(2.00)$ & $4.13(1.89)$ & $4.51(1.69)$ & $0.55(0.01)$ & $1.53(0.01)$ \\
\hline It comes to me in pieces with missing bits. & $3.56(1.80)$ & $3.21(1.80)$ & $3.61(1.83)$ & $0.32(0.01)$ & $2.58(0.01)$ \\
\hline My memory is based on details specific to my life. & $5.26(1.63)$ & $5.37(1.61)$ & $5.54(1.42)$ & $0.24(0.01)$ & $0.53(0.01)$ \\
\hline The event occurred once & $1.75(0.90)$ & $1.82(0.94)$ & $2.00(0.93)$ & $0.53(0.01)$ & $1.67(0.01)$ \\
\hline \multicolumn{6}{|l|}{ Impact of Events Scale (IES-R) } \\
\hline IES: total & $39.9(17.44)$ & $36.5(12.85)$ & $41.0(17.39)$ & $13.71(0.12)^{* * *}$ & $4.87(0.03)^{*}$ \\
\hline IES: avoidance & $15.7(7.45)$ & $14.4(6.20)$ & $15.9(6.67)$ & $14.76(0.13)^{* * *}$ & $2.91(0.02)^{\dagger}$ \\
\hline IES: intrusions & $14.9(7.36)$ & $13.5(5.55)$ & $15.3(7.31)$ & $4.88(0.05)^{*}$ & $4.05(0.02)^{*}$ \\
\hline IES: hyperarousal & $9.2(4.56)$ & $8.5(3.24)$ & $9.8(5.01)$ & $6.07(0.06)^{*}$ & $5.33(0.03)^{*}$ \\
\hline
\end{tabular}

$*=P<.05, * *=P<.01, * * *=P<.001,{ }^{\dagger}=P<.10$

$\eta^{2}=$ eta squared

Neg@ T1 = Negative event condition at Time 1

Neg@T2 = Negative event condition at Time 2

Pos@ $\mathrm{T} 1=$ Positive event condition at Time 1 


\section{Methods}

Participants

A total of 238 participants (152 females) were recruited from the University of North Texas to participate in the study. Participants ranged in age from 18 to 38, with an average age of 20.6 years. Participants received partial course credit for their participation.

\section{Materials}

\section{Event Nomination}

Participants were asked to nominate different events from their lives, including an event from high school, an event from the first week of college, an event from vacation, a very negative personal event, a very positive personal event, an event from elementary school, an event from a time they went shopping, an event from a time they were at a restaurant, an event from a time they were bored, and an event from a time they were with a close friend. For each event participants received the following instructions: "Please write a brief description of this event, which need be intelligible only to you, but that is specific enough to remind you of that unique event at a later time." The purpose of having all participants nominate 10 events from their lives (not just the positive and negative events) was to distract the positive event group from the negative event they nominated, thus limiting the amount of attention drawn to this event.

\section{Autobiographical Memory Questionnaire}

The Autobiographical Memory Questionnaire (AMQ; Rubin et al. 2003b) is a self-report measure used to assess specific properties of a nominated memory. Participants indicate their level of agreement with each item using a 7-point scale. Each item is designed to measure a different phenomenological property of an autobiographical memory. Therefore, there are no subscales and items are typically analyzed individually rather than as a composite score. However, items can be grouped conceptually. A list of the items is included in Table 1.

\section{Impact of Events Scale-Revised}

The Impact of Events Scale-Revised (IES-R; Weiss and Marmar 1997) is a 22-item questionnaire designed to measure PTSD symptoms. The IES-R consists of three subscales that measure intrusiveness of the negative event (i.e. "I thought about it when I didn't mean to"), avoidance of the negative event (i.e. "I tried not to talk about it"), and hyperarousal symptoms (i.e. "I was jumpy and easily startled"). Items are scored on a 5-point scale from 0 ("not at all") to 4 ("extremely"). Reliability ranges from $\alpha=0.79$ to 0.92 . Reliability in the current study was $\alpha=0.95$ at Time 1 and $\alpha=0.92$ at Time 2 .

\section{Procedure}

At Time 1, all participants nominated the aforementioned 10 events from their lives, which included a very negative event and a very positive event. Participants were randomly assigned to one of two groups, either the positive event condition or the negative event condition. Participants in the positive event condition then completed the AMQ and the IES in reference to their nominated positive event. Participants in the negative event condition completed the AMQ and IES in reference to their negative event. Thus all participants nominated a very negative event, but only participants in the negative event condition completed the AMQ and IES in reference to the negative event. Time 2 occurred between 35 and 45 days after the first session. At the second session, all participants were reminded of the very negative event they nominated at Time 1 . All participants then completed the AMQ and the IES in regards to their negative event.

\section{Results}

Participants nominated a wide variety of negative and positive events. Nominated negative events included romantic break-ups, death of a loved one, parents' divorce, and conflict in romantic relationships. Nominated positive events included first dates, falling in love, graduating from high school, starting college, and academic successes. A total of 191 of the 238 participants (80\%) completed both sessions. Completers did not significantly differ from the non-completers on any of the AMQ items or IES scores in the first session (all $P$ 's $>.05$ ).

We first tested whether the AMQ items related to emotional intensity and visceral emotions and IES scores decreased from Time 1 to Time 2 for participants in the negative event condition. Although the AMQ is composed of 25 items and the IES has a total score and three subscales, totaling 29 different analyses, we did not make any Bonferonni adjustments. The reasons for this are (1) this study is an attempt to replicate previous findings, and (2) we were looking for a specific pattern of effects, such that there would be changes in the AMQ items related to emotional reactivity (more specifically, emotional intensity and the four items related to visceral reactions), involuntary recall, 
and in the IES scores. We did not expect any changes in the remaining AMQ items. Because nominated negative events that are more recent may be more likely to evidence decreases in our measures due to the mere passage of time, months-since-event was included as a covariate. Repeated measures ANCOVAs were conducted on each measure, with time as the predictor variable and months-since-event as the covariate. As can be seen in Table 1, participants in the negative event condition evidenced significant decreases in emotional intensity, two (heart and tense) of the four visceral reactions with a non-significant trend for a third (butterflies), the IES total score, and all three of the IES subscales (intrusions, avoidance, and hyperarousal). There were also significant decreases in persuaded, negative emotions, strong emotions, talked about, and thought about.

Since participants in the positive event condition did not complete any measures related to their nominated negative event at Time 1, we cannot examine change scores across the two sessions. However, since all participants completed the AMQ and IES in reference to their nominated negative event at Time 2, we can test for differences between the two groups at Time 2. As can be seen in the rightmost column of Table 1, the results generally supported the hypotheses. Participants in the negative event condition reported less emotionality associated with the event, including lower ratings of emotional intensity, all four visceral reactions (e.g. heart, tense, sweaty, butterflies), total IES scores, and two of the three subscales (intrusions and hyperarousal), with a non-significant trend in the expected direction for the third subscale (avoidance). Participants in this condition also scored lower on reliving, back to the time, and out of the blue. This pattern of results is very similar to the pattern of results reported in Rubin et al. (2010).

\section{Discussion}

The results of the current study generally supported the hypotheses. Participants who were randomly assigned to complete the AMQ and IES in reference to the same negative event, relative to participants who did the same for a positive event, evidenced decreases in measures of emotional intensity, visceral emotional reactions, involuntary recall, and IES scores. These are the same properties that differ between stressful and non-stressful memories (Rubin et al. 2008, 2011), thus these are the properties that we would expect would change if distress levels associated with the event were reduced. No reliable changes were observed in measures of sensory features and language, narrative, and specificity. This pattern of results replicates those reported in Rubin et al. (2010, Exp 4). This successful replication using the revised methodology suggests that it is specifically completing memory questionnaires about a negative event that is therapeutic. The effect is not due to completing memory questionnaires about any event. This finding gives credence to the notion that extinction is the mechanism responsible for the observed therapeutic effects. In an extinction paradigm, only exposure to the negative event will lead to decreases in distress related to that event. We found no evidence that exposure to an unrelated event (a nominated positive event) had any measureable effect on the negative event.

The results of this study should be considered in light of several limitations. First, due to the study design, we were unable to obtain change scores for participants in the positive event condition. However, our large sample size gave us sufficient power to conduct a between-subjects analysis. Second, the effects sizes obtained in the current study were relatively small. This small effect size is not surprising, given that the 'dose' of exposure was also relatively small. In addition, a non-clinical sample was used. Larger effect sizes may be expected if this intervention was used with a clinical sample. Third, we did not make any statistical corrections for multiple comparisons. No such corrections were made because we were attempting to replicate a specific pattern of results. Nevertheless, the reliability of this pattern of results should be considered in light of the fact that no statistical corrections for multiple comparisons were made. Future research should examine the utility of completing autobiographical memory questionnaires in other populations, such as mental health outpatients or medical patients.

These findings have implications for expressive writing research. Researchers investigating the effects of expressive writing should carefully consider the questionnaires that they include in their protocols. Our results suggest that completing detailed questionnaires assessing phenomenological characteristics of a negative event may result in reductions in distress levels associated with the event. Therefore, use of these types of questionnaires could interfere with an expressive writing intervention. Additionally, the AMQ may be useful as a guide to exposure therapy. Mental health professionals could use individual's responses to the AMQ to focus their exposure work. For example, if the individual reports high levels of visceral reactivity to the negative event rather than high levels of reliving, the clinician could choose to focus on reducing visceral reactions first. Overall, the current results suggest that completing the AMQ for a memory of a past negative event is similar to the extinction that occurs during exposure-type interventions.

\section{References}

American Psychiatric Association. (2000). Diagnostic and statistical manual of mental disorders (4th ed., Text Revision). Washington, DC: American Psychiatric Association. 
Boals, A., \& Schuettler, D. (2009). PTSD symptoms in response to traumatic and non-traumatic events: The role of respondent perception and A2 criterion. Journal of Anxiety Disorders, 23, $458-462$.

Breslau, N., Davis, G. C., Andreski, P., \& Peterson, E. (1991). Traumatic events and posttraumatic stress disorder in an urban population of young adults. Archives of General Psychiatry, 48, 216-222.

Buckley, T. C., Green, B. L., \& Schnurr, P. P. (2004). Trauma, PTSD, and physical health: Clinical issues. In J. P. Wilson \& T. M. Keane (Eds.), Assessing Psychological Trauma and PTSD (pp. 441-465). New York, NY: Guilford Press.

Frattaroli, J. (2006). Experimental disclosure and its moderators: A meta-analysis. Psychological Bulletin, 132, 823-865.

Frueh, C. B., Henning, K. R., Pellegrin, K. L., \& Chobot, K. (1997). Relationship between scores on anger measures and PTSD symptomatology, employment, and compensation-seeking status in combat veterans. Journal of Clinical Psychology, 53, 871-878.

Gold, S. D., Marx, B. P., Soler-Baillo, J. M., \& Sloan, D. M. (2005). Is life stress more traumatic than traumatic stress? Journal of Anxiety Disorder, 19, 687-698.

Institute of Medicine. (2008). Treatment of posttraumatic stress disorder: An assessment of the evidence. Washington, DC: The National Academies Press.

Jordan, B. K., Marmar, C. R., Fairbank, J. A., Schlenger, W. E., Kulka, R. A., Hough, R. L., et al. (1992). Problems in the families of male Vietnam veterans with posttraumatic stress disorder. Journal of Consulting and Clinical Psychology, 60, 916-926.

Keim, J. M., Malesky, L. A., \& Strauser, D. R. (2003). Posttraumatic stress disorder (PTSD), life satisfaction, and work personality: Exploring the relationship with disability. Journal of Applied Rehabilitation Counseling, 34, 41-45.

Kessler, R. C., Sonnega, A., Bromet, E., Hughes, M., \& Nelson, C. B. (1995). Posttraumatic stress disorder in the National Comorbidity Survey. Archives of General Psychiatry, 52, 1048-1060.

Kilpatrick, D. G., Ruggiero, K. J., Acierno, R., Saunders, B. E., Resnick, H. S., \& Best, C. L. (2003). Violence and risk of PTSD, major depression, substance abuse/dependence, and comorbidity: Results from the National Survey of Adolescents. Journal of Consulting and Clinical Psychology, 71, 692-700.

Koso, M., \& Hansen, S. (2006). Executive function and memory in posttraumatic stress disorder: a study of Bosnian war veterans. European Psychiatry, 21, 167-173.
Krakow, B., Germain, A., Warner, T. D., Schrader, R., Koss, M., Hollifield, M., et al. (2001). The relationship of sleep quality and posttraumatic stress to potential sleep disorders in sexual assault survivors with nightmares, insomnia, and PTSD. Journal of Traumatic Stress, 14, 647-665.

Long, M. E., Elhai, J. D., Schweinle, A., Gray, M. J., Grubaugh, A. L., \& Frueh, B. C. (2008). Differences in posttraumatic stress disorder diagnostic rates and symptom severity between criterion A1 and non-criterion A1 stressors. Journal of Anxiety Disorders, $22,1255-1263$.

Nemeroff, C. B., Bremner, J. D., Foa, E. B., Mayberg, H. S., North, C. S., \& Stein, M. B. (2006). Posttraumatic stress disorder: A stateof-the-science review. Journal of Psychiatric Research, 40, $1-21$.

Rubin, D. C., Boals, A., \& Berntsen, D. (2008). Memory in posttraumatic stress disorder: Properties of voluntary and involuntary, traumatic and non-traumatic autobiographical memories in people with and without PTSD symptoms. Journal of Experimental Psychology: General, 137, 591-614.

Rubin, D. C., Boals, A., \& Klein, K. (2010). Autobiographical memories for very negative events: The effects of thinking about rating memories. Cognitive Therapy and Research, 34, 35-48.

Rubin, D. C., Dennis, M. F., \& Beckham. J. C. (2011). Autobiographical memory for stressful events: The role of autobiographical memory in posttraumatic stress disorder. Consciousness and Cognition, 20, 840-856.

Rubin, D. C., Feldman, M. E., \& Beckham, J. C. (2003a). Reliving, emotions, and fragmentation in the autobiographical memories of veterans diagnosed with PTSD. Applied Cognitive Psychology, 18, 17-35.

Rubin, D. C., Schrauf, R. W., \& Greenberg, D. L. (2003b). Belief and recollection of autobiographical memories. Memory \& Cognition, 31, 887-901.

Sloan, D. M., \& Marx, B. P. (2004). Taking pen to hand: Evaluating theories underlying the written disclosure paradigm. Clinical Psychology: Science and Practice, 11, 121-137.

Van Hooff, M., McFarlane, A. C., Baur, J., Abraham, M., \& Barnes, B. J. (2009). The stressor criterion-A1 and PTSD: A matter of opinion? Journal of Anxiety Disorders, 23, 77-86.

Weiss, D. S., \& Marmar, C. R. (1997). The impact of events scalerevised. In J. P. Wilson \& T. Martin (Eds.), Assessing psychological trauma and PTSD (pp. 399-411). New York, NY: Guilford Press. 